\title{
Nanoparticles of Metals Oxides Preparation and Characterization
}

\author{
Valery Svetlichnyi, Ivan Lapin, Daria Goncharova, Anastasiia Shabalina \\ Tomsk State University \\ Lenina ave., 36, Tomsk, Russia 634050 \\ v_svetlichnyi@bk.ru; 201kiop@mail.ru; dg_va@list.ru; shabalinav@spti.tsu.ru
}

\begin{abstract}
Water dispersions of four metal oxides nanoparticles were synthesized by pulsed laser ablation of metallic targets (Ce, $\mathrm{Cu}$, $\mathrm{Ti}, \mathrm{Zn}$ ) in water. The fundamental harmonic of nanosecond Nd:YAG laser was used. Nanocrystalline powders of oxides were obtained from the dispersions. The composition and structure of the materials obtained were investigated. The average size of the crystallites was found to be 10-20 nm. Cubic $\mathrm{CeO}_{2}$ and $\mathrm{Cu}_{2} \mathrm{O}$, wurtzite-type $\mathrm{ZnO}$ and anatase/brookite mixture of $\mathrm{TiO}_{2}$ were identified in products. $\mathrm{CeO}_{2}$ was obtained from metallic Ce target for the first time. As prepared nanostructured semiconductors can be used in catalysis and photocatalysis, sunscreen technology, in biomedicine, and as antibacterial agents.
\end{abstract}

Keywords: nanoparticles, titania, ceria, zinc oxide, copper oxide, pulsed laser ablation

\section{Introduction}

Semiconductor nanoparticles are widely used in different fields of science and technology. Cerium dioxide $\mathrm{CeO} 2$ is a unique functional material that is applied in catalysis in a variety of different processes. It may be both a carrier and an active component [1-3]. In biomedicine cerium oxide is also used quite wide. Nanostructured copper oxides $\left(\mathrm{Cu}_{2} \mathrm{O}, \mathrm{CuO}\right)$ are applied in a large variety of fields. It is used as catalyst, as antibacterial agent, in optics, etc. Nano-dispersed TiO2 is applied in "green technologiy" in photovoltaic devices for solar energy [4], in production of bactericidal materials [5], and sunscreens [6]. One of the most prospective fields of its application is environmental photocatalysis for air and water purification [7]. Zinc oxide [8] is a wide-gap semiconductor (band gap of $3.37 \mathrm{eV}$ ) that finds its application in optoelectronics, catalysis, sensorics, biomedicine, food industry, and other fields.

There is a large number of methods for these materials obtaining, and chemical are the most popular once. But chemical methods are often complicated, expansive; they require using precursors that can contaminate the product. In our opinion one of the most prospective methods for synthesis of "pure" nanoparticles is pulsed laser ablation (PLA) of bulk targets in liquid. This method allows controlling effectively the size, structure, composition, and properties of nanoparticles obtained by varying of laser parameters, reaction media, and by introducing of different additives [9-11]. There are some references of preparation $\mathrm{ZnO}, \mathrm{Cu}_{2} \mathrm{O}, \mathrm{CuO}$ and $\mathrm{TiO}_{2}$ in literature with using this method. But all of the materials obtained showed different structure, composition and properties. In case of obtaining of $\mathrm{CeO}_{2}$ there are no references of ablation of metallic Ce target. And the aim of the present work is to obtain pure semiconductors nanoparticles by pulsed laser ablation of metallic targets $(\mathrm{Ce}, \mathrm{Cu}, \mathrm{Ti}, \mathrm{Zn})$ in water, and to study the materials obtained.

\section{Experimental}

Nanoparticles water dispersions were obtained using the experimental setup and the procedure of obtaining are described in [12]. The radiation of the fundamental harmonic of Nd: YAG laser was used (1064 nm, $7 \mathrm{~ns}, 150 \mathrm{~mJ}, 20 \mathrm{~Hz})$. Short-focus lens $(\mathrm{F}=40 \mathrm{~cm})$ focused the radiation at the target surface through the wall of $50 \mathrm{ml}$ glass reactor. Target was moved in the plane XY, perpendicular to the optical axis. Obtaining of nanoparticles in water took different time for different targets. The size and structure of the particles were examined by transmission electron microscopy (TEM CM 12, Philips), $120 \mathrm{kV}$. Freshly obtained dispersions were deposited on copper grids with amorphous carbon and allowed to dry. The composition of nanostructured powders obtained was studied by X-ray diffraction (Shimadzu XRD 6000). 


\section{Results and discussion}

Figure 1 presents TEM-images of nanoparticles from water dispersions obtained by PLA. It can be seen, that particles obtained from $\mathrm{Ce}$ and $\mathrm{Cu}$ targets can be both big (up to $70 \mathrm{~nm}$ for $\mathrm{Ce}$ ) and small (10, and even $5 \mathrm{~nm}$ for copper), and mostly show spherical shape. Smaller particles form not very large agglomerates. In case of Ti target particles are spherical too, but the size is smaller, and agglomerates are bigger and thicker. Nanoparticles from Zn target show three different shapes: rods, spheres and hexagons, with the average size about $15 \mathrm{~nm}$.

XRD data, presented on Figure 2, reveals that all the particles are metal oxides. Cubic $\mathrm{CeO}_{2}$ and $\mathrm{Cu}_{2} \mathrm{O}$ crystals and wurtzite-type $\mathrm{ZnO}$ are the only components of corresponding water nanoparticles dispersions. In case of $\mathrm{TiO}_{2}$ there are two polymorphic modifications of titania - anatase and brookite (about 35\%). All the data obtained are summarized in Table 1. It is clearly seen, that the parameters of ablation are connected with the thermal characteristics of target materials. Catalytic, photocatalytic and antibacterial properties of as-prepared semiconductor nanoparticles were further investigated.

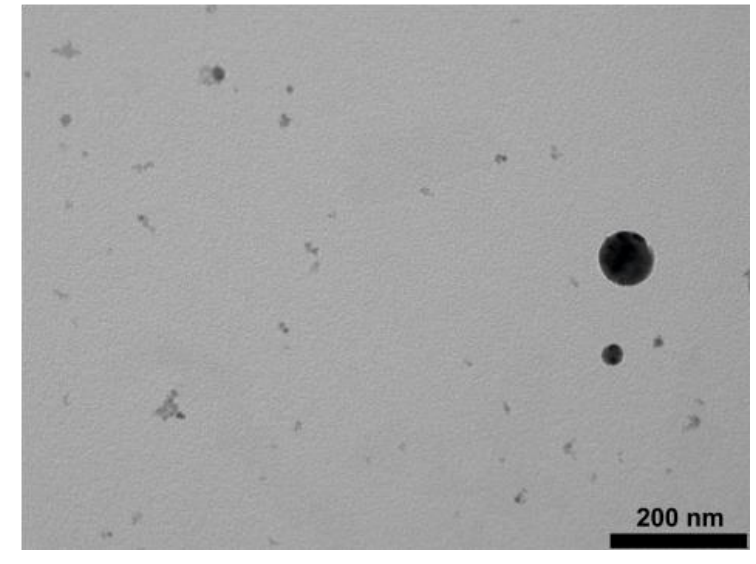

a

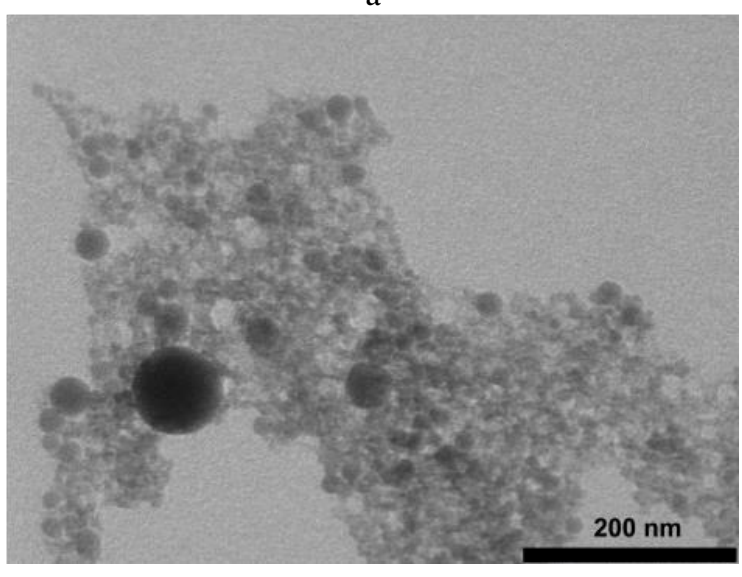

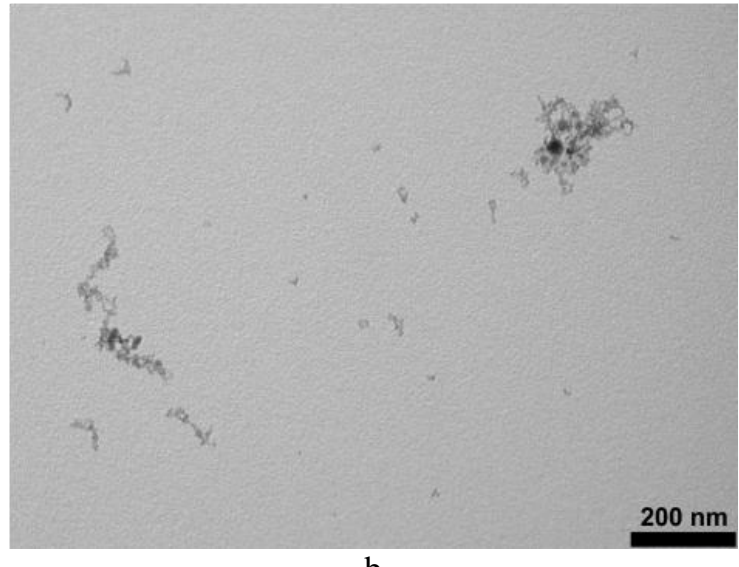

$\mathrm{b}$

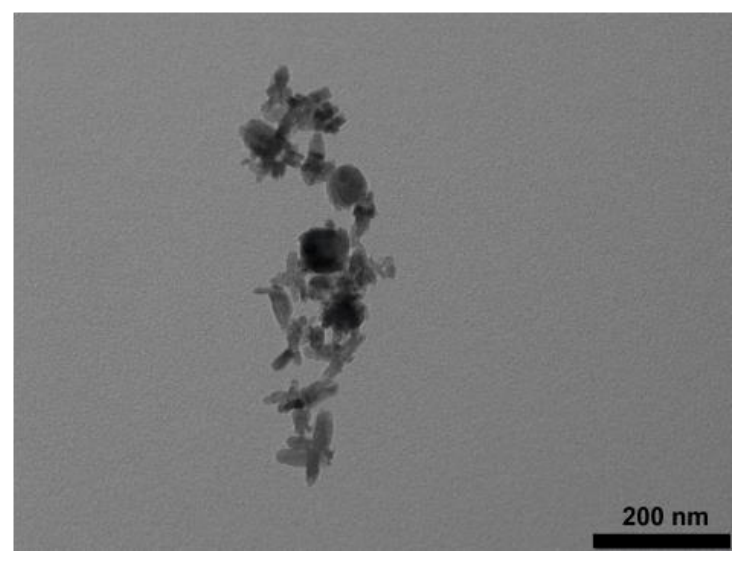

d

Fig. 1: TEM images of nanoparticles from water dispersions obtained by PLA: (a) - from Ce target; (b) - from $\mathrm{Cu}$ target; (c) - from Ti target; (d) - from Zn target.

\section{Conclusion}

Water dispersions of four metal oxides nanoparticles were synthesized using pulsed laser ablation of metallic targets $(\mathrm{Ce}, \mathrm{Cu}, \mathrm{Ti}, \mathrm{Zn})$ in water. For the first time, $\mathrm{CeO}_{2}$ was obtained from metallic $\mathrm{Ce}$ target, not from $\mathrm{CeO} 2$ powder or cerium salts solution ablation. The materials obtained were characterized. Among the products obtained the phases of cubic $\mathrm{CeO}_{2}$ and $\mathrm{Cu}_{2} \mathrm{O}$, wurtzite-type $\mathrm{ZnO}$ and anatase/brookite mixture of $\mathrm{TiO}_{2}$ were found. The average size of the crystallites was 10$20 \mathrm{~nm}$. As prepared nanostructured semiconductors can be used for different applications, $\mathrm{ZnO}$ and $\mathrm{Cu}_{2} \mathrm{O}$ have shown high antibacterial activity, $\mathrm{CeO}_{2}$ - catalytic, and $\mathrm{TiO}_{2}$ - photocatalytic activity. 


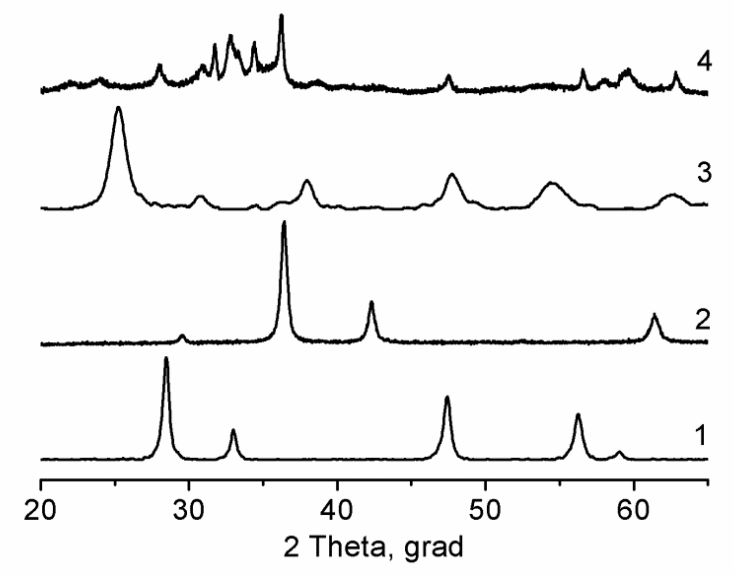

Fig. 2: XRD patterns of powders from water dispersions obtained by PLA: (1) - from Ce target; (2) - from Cu target; (3) - from Ti target; (4) - from Zn target.

\section{Acknowledgements}

The work is performed within the state assignment of Russian Ministry of Education and Science (Assignment \#2014/223, Project code \#1347).

\section{References}

[1] A. Trovarelli, "Catalytic Properties of Ceria and CeO2-Containing Materials," Catal. Rev.: Sci. and Eng., vol. 38, no. 4, pp. 439-520, 1996.

[2] J. Kaspar, P. Fornasiero, and M. Graziani, "Use of CeO2-based oxides in the three-way catalysis," Catal. Today., vol. 50, no. 2, pp. 285-298, 1999.

[3] R. V. Gulyaev, E. M. Slavinskaya, S. A. Novopashin, D. V. Smovzh, A. V. Zaikovskii, D. Osadchii, O. A. Bulavchenko, S. V. Korenev, and A. I. Boronin, "Highly active PdCeOx composite catalysts for low-temperature CO oxidation, prepared by plasma-arc synthesis," Appl. Catal. B, vol. 147, pp. 132-143, 2014.

[4] M. Gratzel, "Sol-Gel Processed TiO2 Films for Photovoltaic Applications," J. Sol-Gel Sci. Technol., vol. 22, pp. 7-13, 2001.

[5] K. Sunada, Y. Kikuchi, K. Hashimoto, and A. Fujishima, "Bactericidal and Detoxification Effects of TiO 2 Thin Film Photocatalysts," Environ. Sci.\& Tech., vol. 32, no. 5, pp. 726-728, 1998.

[6] Z. A. Lewicka, A. F. Benedetto, D. N. Benoit, W. W. Yu, J. D. Fortner, and V. L. Colvin, "The Structure, Composition, And Dimensions Of TiO2 and ZnO Nanomaterials in Commercial Sunscreens," J. Nanopart. Res., vol. 13, pp. 36073617, 2011.

[7] A. Fujishima, T. N. Rao, and D. A. Tryk, "Titanium Dioxide Photocatalysis," J. Photochem. Photobiol. C., vol. 1, no. 1, pp. 21, 2000.

[8] Z. L. Wang, J. Phys. Condens. Matter., vol. 16, no. 25, pp. R829-R858, 2004.

[9] D. Tan, S. Zhou, J. Qiu, and N. Khusro, "Preparation of functional nanomaterials with femtosecond laser ablation in solution," J. Photochem. Photobiol. C, vol. 17, pp. 50-68, 2013.

[10] D. Goncharova, I. Lapin, and V. Svetlichnyi, "Synthesis of CdS nanoparticles by laser ablation of metallic cadmium target in presence different precursors," Adv. Mater.Res., vol. 1085, pp. 182-186, 2015.

[11] T. Sasaki, Y. Shimizu, and N. Koshizaki, "Preparation of metal oxide-based nanomaterials using nanosecond pulsed laser ablation in liquids," J. Photochem. Photobiol. A, vol. 182, pp. 335-341, 2006.

[12] V. A. Svetlichnyi, T. I. Izaak, I. N. Lapin, D. O. Martynova, O. A. Stonkus, A. I. Stadnichenko, and A. I. Boronin, "Physicochemical investigation of nanopowders prepared by laser ablation of crystalline silicon in water," Adv. Powd. Tech., vol. 26, no. 2, pp. 478-786, 2015. 